\title{
Effects of lumbar stabilization exercise according to correct verbal instructions in pain and muscle strengthening of low back pain patient
}

\author{
Sungha Jia, Dongjin Lee ${ }^{b}$

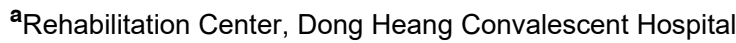

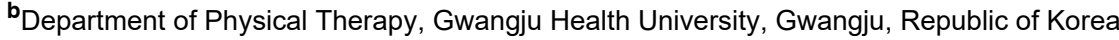

Objective: This study was aimed at investigating the effects of lumbar stabilization exercise according to correct verbal instructions in pain and muscle strengthening of the low back pain patients.

Design: A randomized controlled trial.

Methods: Twenty subjects with low back pain were selected. They were randomly assigned to one of two groups (10 in each group): namely the lumbar stabilization exercise and lumbar stabilization exercise according to the correct verbal instructions group. The lumbar stabilization exercise group performed lumbar stabilization exercises for 6 weeks (5 times a week). The lumbar stabilization exercise according to correct verbal instructions group performed lumbar stabilization exercise according to correct verbal instructions for 6 weeks ( 5 times a week). We measured pain, muscle power, proprioception, and body balance before and after exercise by using visual analog scale (VAS), digital handheld dynanometer, Joint repositioning error, time up and go test respectively.

Results: We found statistically significant differences in pain, muscle power, proprioception, and body balance in lumbar stabilization exercise and lumbar stabilization exercise according to correct verbal instructions group, before and after $(p<0.05)$.

Conclusions: We confirmed the effect of lumbar stabilization exercise according to correct verbal instructions. Thus we thought these results could be used as basic data and reference for low back pain. But we need more study effect of correct verbal instructions on other exercises.

Key Words: Low back pain, Stabilization exercise, Verbal instructions

서론

현대사회에서 인터넷과 같은 정보매체의 발달로 좌식 생활 시간이 증가하고, 사무화나 자동화된 생활환경에서 신체활동의 감소, 자세불량 및 운동부족 등으로 건강상 문 제들이 나타나고 있다[1]. 이 중 요통은 대표적인 근골격계 장애로 발병률이 높은 질환이다[2]. 요통은 나이와 성별을 불문하고 평생에 한번 이상 겪게 될 확률이 $60 \sim 80 \%$ 에 이 르고, 그 중 5 15\%는 만성요통으로 이어지게 된다[3]. 요 통은 요추부 근육의 약화 및 고유감각을 저하시키며, 요추 부 불안정성의 증가와 균형능력 저하를 초래한다[4].
요통을 치료하는 방법은 의료기기 등을 이용한 치료가 널리 적용되어 왔지만[5], Lee [6]는 요통치료를 위한 근이 완의 보존적 치료와 의료기기 등을 이용한 치료의 효과는 대부분 일시적이라고 하였고, Mather [7]는 신체활동 없는 치료법은 신체 지지 근육의 약화로 회복에 부정적이라고 보고하였다.

만성요통의 악순환을 끊을 치료로 신체활동을 통한 운 동요법이 제시되었고[8], 운동요법은 통증감소와 장애 개 선에 효과적이며[9], 또한 Kelly [10]는 운동요법을 통해 약화된 근력을 강화하고 긴장된 근육을 이완하여 신체의 움직임과 유연성을 증가시킬 수 있다고 보고하였다. 요통

Received: Mar 2, 2021 Revised: Mar 3, 2021 Accepted: Mar 4, 2021

Corresponding author: Dongjin Lee (ORCID https://orcid.org/0000-0002-9877-5837)

Department of Physical Therapy, Gwangju Health University, Gwangju, Republic of Korea

Tel: (82 for International)-010-5436-5147 Fax:062-958-7786 E-mail: don4114@gmail.com

This is an Open-Access article distributed under the terms of the Creative Commons Attribution Non-Commercial License (http://creativecommons.org/licenses/ by-nc/4.0) which permits unrestricted non-commercial use, distribution, and reproduction in any medium, provided the original work is properly cited.

Copyright () 2021 Korean Academy of Physical Therapy Rehabilitation Science 
치료에 적용되는 운동요법에는 Williams 운동, Mckenzie 운동, Pilates 운동 등이 적용되어 왔고[11], 이 외에도 볼 운동, 슬링 운동, 스트레칭, 안정화 운동 등도 있으며[12], 등속성, 등척성 운동기기를 이용한 방법들도 있다[13].

이러한 방법들 중 요부안정화 운동은 그 정의가 명확하 지는 않지만 보편적으로 소근육과 대근육을 동시에 활성 화시켜 미세손상이나 재발성 통증으로부터 척추관절 구조 들을 보호하기 위한 운동으로[14], 적절한 신경근육의 조 절과 협응력을 유지하면서 허리와 골반부위의 안정성에 관여하는 근육들을 강화시켜 척추 안정성을 증가시키는 방법이라고 정의하였다[15]. 이는 근육의 움직임 패턴을 훈련시킴으로써 척추의 안정화를 증가시키고, 요통을 유 의하게 감소시킨다고 하였다[16].

요부의 안정화 및 보상작용은 보통 치료사의 손이나 다 양한 피드백으로 통제하지만 이는 스스로 하기 어렵고 피 드백이 없으면 효과적이지 않아, 요부를 안정시키고 불필 요한 보상작용을 줄이는 운동방법의 연구가 진행되어 왔 다[17]. 안정화 운동을 실시할 때 보상작용을 줄이고 운동 효과를 높이기 위한 방법으로 구두지시가 있다. 주로 초기 안정화 운동 적용 시 환자들이 운동패턴을 인식하고, 근안 정화를 목표시 재활을 도울 수 있는 방법으로 구두지시가 제안되어 왔다[18]. 운동시 구두지시를 추가하였을 때 선 택적인 근활성화가 일어나며[19], 구두지시가 근활성도의 변화 또는 독립적 활성화를 시키고[20], 근활성도를 높이 기 위해서는 불안정 지지면이나, 높은 부하보다 적절한 구 두지시를 사용하는 것이 더 효과적이라고 하였다[21].

이에 본 연구에서는 구두지시의 효과에 주목하여 올바른 구두지시에 따른 요부안정화 운동을 요통환자에게 적용하 여 통증 및 근력강화에 미치는 영향을 확인하고자 하였다.

\section{연구 방법}

\section{연구 대상}

본 연구는 $\mathrm{G}$ 시의 $\mathrm{D}$ 병원에서 입원 및 외래로 진료 및 치
료를 받고 있는 요통환자를 대상으로 구두 또는 서면으로 연구 목적과 방법을 충분히 설명한 후 대상을 모집하였다. 자발적 동의 후 연구를 진행하였고 헬싱키선언에 따른 윤 리기준을 준수하여 진행하였다. 대상자는 비특이성 요통 을 진단받고[22], 치료 중인 요통환자를 선정하였고, 압박 골절, 계통적 암 질환자, 중추신경계 이상자, 전정기관 이 상자, 심혈관계 이상자는 대상자에서 제외하였다.

선정된 대상자들은 실험참가 순서대로 10 명씩 요부안 정화 운동 그룹과 올바른 구두지시에 따른 요부안정화 운 동 그룹으로 구분하였다. 대상자들의 일반적인 특성은 다 음과 같고(Table 1), 유의한 차이가 없었다.

\section{연구 절차}

본 연구는 본 연구는 무작위 임상실험으로 요통환자 대 상자 20 명을 실험 참가순서에 따라 임의적으로 각각 10 명 씩 대조군인 요부안정화 운동 그룹, 실험군인 올바른 구두 지시에 따른 요부안정화 운동 그룹으로 구분하여 연구기 간은 총 6 주를 진행하고 사전 및 사후 측정을 실시하였다.

대조군과 실험군의 사전 및 사후 측정에서 올바른 구두 지시가 통증 및 근력강화에 미치는 영향을 확인하기 위해 Visual Analog Scale (VAS), 디지털 근력계(Commander Power track II Muscle tester JT-AA104; JTECH, USA), 관절 재위치오류(Joint Repositioning Error), 일어나 걷기 검사(Time Up and Go test, TUG)를 사용하여 통증, 근력, 고유감각, 균형을 측정하였다.

\section{중재 방법}

\section{요부안정화 운동}

본 연구에서는 요부 안정화 운동은 요부근육 활성과 안 정에 초점을 둔 FRANC 등[23]의 방법을 참고하여 실시하 였다. 각 운동마다 10 회 3 세트로 구성하였다. 대조군인 요 부안정화 그룹은 사전교육 후 6 주간 주 5 회 30 분간 자가적 으로 운동을 시행하였다.

요부안정화 운동 방법은 첫째 네발기기 자세에서 배꼽

Table 1. General Characteristics of Participants

$(n=20)$

\begin{tabular}{llll}
\hline Characteristics & $\begin{array}{l}\text { Control group } \\
(\mathbf{n = 1 0})\end{array}$ & $\begin{array}{l}\text { Experimental group } \\
(\mathbf{n = 1 0})\end{array}$ & $\mathbf{p}$ \\
\hline $\begin{array}{l}\text { Sex } \\
\text { (male / female) }\end{array}$ & $4 / 6$ & $3 / 7$ & 0.773 \\
Age (years) & $36.10(2.86)$ & $38.30(2.48)$ & 0.794 \\
Height (cm) & $163.60(5.80)$ & $165.20(5.02)$ & 0.853 \\
Weight $(\mathrm{kg})$ & $64.30(2.48)$ & $66.80(5.73)$ & 0.831 \\
\hline
\end{tabular}

The values are presented mean (SD)

Control group: lumbar stabilization exercise group, Experimental group: lumbar stabilization exercise according to correct verbal instructions. 
당기기 동작을 만들고 10 초 동안 유지하도록 하였다. 둘째 바로 누운 자세에서 무릎을 구부린 후 배꼽 당기기 동작을 만들고 10 초 동안 유지하도록 하였다. 셋째 엎드린 자세에 서 골반의 후방 경사 자세를 만들기 위해 배꼽 당기기 동작 을 만들고 10 초 동안 유지하도록 하였다. 넷째 앉은 자세 에서 직립자세를 유지하게 하고 배꼽 당기기 동작을 만들 어 10 초 동안 유지하도록 하였다. 다섯째 네발기기자세에 서 한 팔 들기와 한 다리 들기를 만들고 배꼽 당기기 동작을 만들고 10 초 동안 유지하도록 하였다. 여섯째 선 자세에서 불안정한 지지면(Balance-pad; Airex AG, Switzerland)을 제공하고 중립적인 자세를 유지하도록 하였다.

\section{올바른 구두지시에 따른 요부안정화 운동}

본 연구에서 올바른 구두지시에 따른 요부 안정화 운동 은 대조군에서 실시한 요부 안정화 운동을 사전교육 후 6 주간 주 5 회 30 분간, 치료사의 구두지시 하에 실시하였다. 치료사는 운동 중 바른 동작과 유지와 불필요한 보상작용 을 줄이도록 구두지시를 하였다.

올바른 구두지시 하에 따른 요부안정화 운동 방법은 첫 째 네발기기 자세에서 “배 집어넣으세요”란 구두 지시을 주 었고 배꼽 당기기 동작을 만들고 10 초 동안 유지하도록 하 였다. 둘째 바로 누운 자세에서 무릎을 구부린 후 “배 집어넣 으세요"란 구두 지시을 주었고 배꼽 당기기 동작을 만들고 10 초 동안 유지하도록 하였다. 셋째 엎드린 자세에서 골반 의 후방 경사자세를 만들기 위해 “엉덩이에 힘주세요”란구 두지시를 주었고 배꼽 당기기 동작을 만들고 10 초 동안 유 지하도록 하였다. 넷째 앉은 자세에서 "허리 펴시고 가슴 넓 히세요”란 구두 지시을 주어 직립자세를 유지하게 하고 배 꼽 당기기 동작을 만들어 10 초 동안 유지하도록 하였다. 다 섯째 네발기기자세에서 한 팔 들기와 한 다리 들기를 만들고 “배 집어 넣으세요”란 구두지시를 주었고 배꼽 당기기 동작 을 만들고 10 초 동안 유지하도록 하였다. 여섯째 선 자세에 서 불안정한 지지면을 제공한 “똑바로 서 계세요”란 구두지 시를 주었고 중립적인 자세를 유지하도록 하였다. 운동 중 불필요한 보상작용 발생시 구두지시로 수정하도록 하였다.

\section{측정방법 및 도구}

\section{통증}

본 연구에서는 Visual Analog Scale (VAS)를 이용하여 사전, 사후에 대상자의 통증을 측정하였다.

시각적 상사 척도는 눈금이 표시되어 있지 않은 막대 위 에 환자가 느끼고 있는 통증의 정도를 표시하게 한 후, 시 작점에서 표시점까지의 거리를 측정하여 점수화하는 방법 이다. 점수는 0 점에서 10 점까지이며, 통증이 없는 상태는 0 으로 하고, 참을 수 없는 통증의 정도는 10 으로 정의하여 측정한다. 높은 재현성을 보이고 있는 통증 척도법으로 통
증강도를 평가하는데 가장 널리 사용되고 있는 방법으로 [24], 본 연구에서는 사전, 사후에 통증을 측정하였다. 시 각적 상사 척도의 검사-재검사 신뢰도 $(\mathrm{r}=.99)$ 와 측정자간 신뢰도(r=1.00)는 매우 높았다[25].

\section{근력}

본 연구에서는 디지털 근력계(Commander Power track II Muscle tester JT-AA104; JTECH, USA)를 사용하여 사전, 사후에 대상자의 근력을 측정하였다.

이 장비는 수량화된 측정값을 위하여 임상에서 이루어 지는 도수 근력 측정을 대신하는 도구이며, 측정치는 파운 드(Ib)의 단위에서 디지털화된 방식으로 기록된 후 $\mathrm{kg}$ 값으 로 변환되고 측정자간 신뢰도는 급간내 관계수(ICCs)값이 0.89에서 0.96 으로 보고되었다[26].

허리의 근력측정은 몸통 굽힘과 몸통 폄을 측정하였고, Roy 등 [27]의 방법을 참고하여 굽힘은 바로 누운 자세에 서 다리 고정 후 가슴에 팔짱을 끼고 상체를 들어올리는 동 작으로 상체에 측정기를 대기 측정하고, 폄은 엎드린 자세 에서 발목을 고정 후 손을 머리 뒤로 깍지를 끼고 상체를 들어올리는 동작으로 상체에 측정기를 대기 측정하였다. 모든 동작은 각각 3 회씩 측정 후 평균값을 내고, 측정 오차 를 줄이기 위해 기구 훈련을 받은 한 사람이 모든 측정을 동일 측정기와 방법으로 시행하였다.

\section{고유감각}

본 연구에서는 관절 재위치오류를 사용하여 사전, 사후 에 대상자의 고유감각을 측정하였다. 이는 목표 위치를 설 정한 후 다시 목표 위치를 재현하도록 하여 처음 목표 위치 와 대상자가 실행한 위치 사이에 나타나는 차이를 측정하 는 검사이다[28]. 본 연구에서는 $\mathrm{Ji}$ 등 [29]의 방법을 참고 하여 허리관절의 관절 재위치오류를 측정하였다.

\section{균형}

본 연구에서는 일어나 걷기 검사(Time Up and Go test, TUG)로 사전, 사후에 대상자의 균형을 측정하였다. 일어 나 걷기 검사는 사람이 팔 없는 의자에서 일어나서 3 미터 를 걷고, 돌아서며, 의자에 다시 걸어서 앉는데 걸리는 시 간을 사용한다. 우수한 측정자내 신뢰도가 측정되었다 (ICC $=0.99)[30]$.

\section{자료 분석}

본 연구에서 측정된 모든 자료의 평균과 표준편차는 SPSS Ver. 18.0을 사용하여 산출하였다. 각 군의 전후 비 교를 위해 대응표본 t검정을 사용하였고 군간 비교를 위해 독립표본 t검정을 이용하였다. 모든 통계학적 분석의 유의 수준은 $\mathrm{p}=0.05$ 로 설정하였다. 


\section{연구 결과}

대상자들에게 올바른 구두지시에 따른 요부안정화 운 동을 실시하고 통증과 근력강화에 미치는 영향을 확인하 기 위한 본 연구 결과는 다음과 같다.

\section{통증}

통증은 각 군에서 실험 후에 유의하게 감소하였고 $(\mathrm{p}<0.05)$, 군간 비교에서도 유의한 차이가 있었다 $(\mathrm{p}<0.05)($ Table 2).

\section{근력}

근력은 허리 굽힘과 폄 모두 각 군에서 실험 후에 유의 하게 증가하였고 $(\mathrm{p}<0.05)$, 군간 비교에서도 굽힘과 폄에서 유의한 차이가 있었다 $(\mathrm{p}<0.05)($ Table 3$)($ Table 4).

\section{고유감각}

고유감각은 각 군에서 실험 후에 유의하게 감소하였고 $(\mathrm{p}<.005)$, 군간 비교에서도 유의한 차이가 있었다 $(\mathrm{p}<0.05)$ (Table 5).

\section{귷형}

균형은 각 군에서 실험 후에 유의하게 감소하였고 $(\mathrm{p}<0.05)$, 군간 비교에서도 유의한 차이가 있었다 $(\mathrm{p}<0.05)$ (Table 6).

\section{고찰}

본 연구에서는 올바른 구두지시에 따른 요부안정화 운

Table 2. Comparison of visual analog scale

$(\mathrm{n}=20)$

\begin{tabular}{lllll}
\hline & & $\begin{array}{l}\text { Control group } \\
(\mathbf{n}=\mathbf{1 0})\end{array}$ & $\begin{array}{l}\text { Experimental group } \\
(\mathbf{n}=\mathbf{1 0})\end{array}$ & $\mathbf{t}(\mathbf{p})$ \\
\hline VAS & Pre & $6.95(1.27)$ & $6.76(1.73)$ & $-1.871(0.132)$ \\
& Post & $4.84(1.22)$ & $3.59(1.53)$ & $-1.54\left(0.000^{*}\right)$ \\
& $\triangle$ & $2.11(0.85)$ & $3.17(0.30)$ & $-1.763\left(0.000^{*}\right)$ \\
\hline
\end{tabular}

The values are presented mean (SD)

Control group: lumbar stabilization exercise group, Experimental group: lumbar stabilization exercise according to correct verbal instructions. VAS: visual analog scale. ${ }^{*} \mathrm{p}<0.05$,

Table 3. Comparison of muscle power of lumbar flexion

$(\mathrm{n}=20)$

\begin{tabular}{lllll}
\hline & & $\begin{array}{l}\text { Control group } \\
(\mathbf{n}=\mathbf{1 0})\end{array}$ & $\begin{array}{l}\text { Experimental group } \\
(\mathbf{n}=\mathbf{1 0})\end{array}$ & $\mathbf{t}(\mathbf{p})$ \\
\hline Muscle power of & Pre & $14.67(5.09)$ & $15.23(5.02)$ & $-1.361(0.153)$ \\
lumbar flexion & Post & $18.52(5.27)$ & $21.00(4.05)$ & \\
& $\triangle$ & $3.85(1.49)$ & $5.77(0.97)$ & $-1.693\left(0.000^{*}\right)$ \\
& $\mathrm{t}(\mathrm{p})$ & $-5.031\left(0.000^{*}\right)$ & $-4.682\left(0.000^{*}\right)$ & \\
\hline
\end{tabular}

The values are presented mean (SD)

Control group: lumbar stabilization exercise group, Experimental group: lumbar stabilization exercise according to correct verbal instructions. ${ }^{*} \mathrm{p}<0.05$

Table 4. Comparison of muscle power of lumbar extension

$(\mathrm{n}=20)$

\begin{tabular}{lllll}
\hline & & $\begin{array}{l}\text { Control group } \\
(\mathbf{n}=\mathbf{1 0})\end{array}$ & $\begin{array}{l}\text { Experimental group } \\
(\mathbf{n}=\mathbf{1 0})\end{array}$ & t (p) \\
\hline Muscle power of & Pre & $14.80(2.51)$ & $15.17(3.43)$ & $-2.024(0.221)$ \\
lumbar extension & Post & $17.52(5.27)$ & $19.23(2.17)$ & $-2.113(0.000 *)$ \\
& $\Delta$ & $2.67(1.79)$ & $4.06(1.27)$ & $-3.982\left(0.000^{*}\right)$ \\
\hline
\end{tabular}

The values are presented mean (SD)

Control group: lumbar stabilization exercise group, Experimental group: lumbar stabilization exercise according to correct verbal instructions. ${ }^{*} \mathrm{p}<0.05$ 
동이 요통환자에게 효과적으로 사용될 수 있음을 확인하는 데 그 목적이 있었으며 이를 위해 요통으로 인해 부정적 영 향을 줄 수 있는 통증, 근력, 고유감각, 균형을 측정하였다.

본 연구의 결과에서는 대조군과 실험군의 사전, 사후 측 정에서 모든 측정에서 유의한 결과를 보였고, 군간 비교에 서도 유의한 차이를 보였다.

본 연구에 적용된 요부안정화 운동은 근육의 움직임과 조절능력을 회복시키고 효율적으로 근력을 증가시켜 요부 의 안정성 및 자세조절에 기여한다고 하였다[31]. 또한 요 부안정화 운동은 일반적인 근력운동보다 근력을 향상시키 는데 더 효과적이고[32], 근신경조직의 반응 속도를 증가 시켜 안정성을 회복시킨다고 하였다[33]. 요부안정화 운동 에 의한 몸통의 안정성 증진은 통증의 재발률이 낮아져 만 성 요통환자에게 높은 수준의 효과를 나타내는 것으로 보 고되었다[34]. 이러한 선행 연구들의 결과들과 본 연구의 결과를 바탕으로 요부 안정화 운동은 요통환자의 기능개 선에 효과적이라고 사료된다.

본 연구의 결과에서 실험군인 올바른 구두지시에 따른 요부안정화 운동 그룹에서 대조군인 요부안정화 운동 그 룹보다 통증, 근력, 고유감각, 균형에서 유의한 결과를 보 여 올바른 구두지시가 운동효과에 더욱 긍적적임을 보여 주고 있다. 이는 선행연구들에서도 운동 중 구두지시를 추 가하였을 때 근 활성도를 변화시키거나 독립적으로 활성 화시킬 수 있다고 하였고[10], 요통환자는 아니지만 파킨 슨환자에게 구두지시를 추가하였을 때 보행속도와 보폭
및 보행주기가 향상되었다고 하였다[35]. 또한 구두지시는 과제 수행의 정확성을 높이고[36], 운동 중 “강하게”라는 구두지시가 추가되면 근활성도가 증가한다고 하였다[37]. 또한 본 연구의 실헌군에서는 구두지시를 동작적인 지시 와 더불어 불필요한 보상동작을 수정하도록 실시하였는 데, 이는 잘못된 동작으로 발생하는 통증 등을 감소시켜 통 증으로 인한 운동공포나 두려움이 감소되는 효과가 있었 을 것으로 사료된다. 이는 움직임에 대한 두려움도 잠재적 인 위험요소가 되며, 운동공포는 통증과 연관된 장애를 일 으키고, 급성에서 만성 근골격계 통증으로 진행시킨다[38] 는 선행연구의 결과와 유사하다고 생각된다.

올바른 구두지시에 따른 운동효과를 확인하기 위해, 추후 본 연구의 요부안정화 운동 외의 운동에서 올바른 구두지시를 적용하여 추가적인 연구가 필요할 것으로 사 료된다.

\section{결론}

본 연구에서는 올바른 구두지시에 따른 요부안정화 운 동이 요통환자의 통증 및 근력강화에 미치는 영향을 확인 하기 위해 통증, 근력, 고유감각, 균형을 측정하여 다음과 같은 결론을 얻었다.

본 연구의 결과에서는 대조군과 실험군의 사전, 사후 측 정에서 모든 측정에서 유의한 결과를 보였고, 군간 비교에 서도 유의한 차이를 보였다.

Table 5. Comparison of proprioception

$(\mathrm{n}=20)$

\begin{tabular}{lllll}
\hline & & $\begin{array}{l}\text { Control group } \\
(\mathbf{n}=\mathbf{1 0})\end{array}$ & $\begin{array}{l}\text { Experimental group } \\
(\mathbf{n}=\mathbf{1 0})\end{array}$ & t (p) \\
\hline Proprioception & Pre & $4.90(0.89)$ & $4.97(1.28)$ & $-2.871(0.230)$ \\
& Post & $2.83(0.42)$ & $1.93(0.66)$ & $-1.542\left(0.000^{*}\right)$ \\
& $\Delta$ & $2.07(0.47)$ & $3.04(0.62)$ & \\
\hline
\end{tabular}

The values are presented mean (SD)

Control group: lumbar stabilization exercise group, Experimental group: lumbar stabilization exercise according to correct verbal instructions. ${ }^{*} \mathrm{p}<0.05$

Table 6. Comparison of body balance

$(\mathrm{n}=20)$

\begin{tabular}{lllll}
\hline & & $\begin{array}{l}\text { Control group } \\
(\mathbf{n}=\mathbf{1 0})\end{array}$ & $\begin{array}{l}\text { Experimental group } \\
(\mathbf{n}=\mathbf{1 0})\end{array}$ & $\mathbf{t}(\mathbf{p})$ \\
\hline Body & Pre & $9.53(4.78)$ & $9.49(3.80)$ & $-1.694(0.361)$ \\
balance & Post & $7.75(4.58)$ & $6.42(3.73)$ & $-1.742\left(0.000^{*}\right)$ \\
& $\triangle$ & $1.78(0.20)$ & $3.07(0.07)$ & $2.343\left(0.000^{*}\right)$ \\
\hline
\end{tabular}

The values are presented mean (SD)

Control group: lumbar stabilization exercise group, Experimental group: lumbar stabilization exercise according to correct verbal instructions. ${ }^{*} \mathrm{p}<0.05$ 
이를 통해 올바른 구두지시가 운동에 효과적임을 확인 하였으나 올바른 구두지시가 효과적인을 확인하기 위해서 는 타운동에서도 올바른 구두지시를 적용하여 추가적인 연구가 필요할 것으로 사료된다.

\section{감사의 글}

이 논문은 2020년도 광주보건대학교 교내연구비의 지 원을 받아 수행된 연구임(2020013).

\section{참고문헌}

1. Shiri R, Solovieva S, Husgafvel-Pursiainen K, Taimela S, Saarikoski, LA, Huupponen R, et al. The association between obesity and the prevalence of low back pain in young adults: the Cardiovascular Risk in Young Finns Study. Am J Epidemiol. 2008;167:1110-1119.

2. Skoffer B. Low back pain in 15- to 16-year-old children in relation to school furniture and carrying of the school bag. Spine (Phila Pa 1976). 2007;32:E713-7.

3. Ferreira PH, Ferreira ML, Maher CG, Herbert RD, Refshauge K. Specific stabilisation exercise for spinal and pelvic pain: A systematic review. Aust J Physiother. 2006;52:79-88.

4. O'Sullivan PB, Burnett A, Floyd AN, Gadsdon K, Logiudice J, Miller D, et al. Lumbar repositioning deficit in a specific low back pain population. Spine. 2003;28:1074-1079.

5. Kudo P, Dainty K, Clarfield M, Coughlin L, Lavoie P, Lebrun C. Randomized, placebo-controlled, double-blind clinical trial evaluating the treatment of plantar fasciitis with an extracoporeal shockwave therapy (ESWT) device: a North American confirmatory study. J Orthop Res. 2006;24:115-23.

6. Coulombe BJ, Games KE, Neil ER, Eberman LE. Core Stability Exercise Versus General Exercise for Chronic Low Back Pain. J Athl Train. 2017;52(1): 71-2.

7. Mathe CG. Effective physical treatment for chronic low back pain. Orthop Clin North Am. 2004;35:57-64.

8. Deyo RA, Weinstein JN. Low back pain. N Engl J Med. 2001;344:363-70.

9. Ko DS, Lee CG, Kim GY, Lee KI, Kim MH, Jeong DI. The Effect of Lumbar Stabilization Exercise on Motor Capacity and Pain in Chronic Low Back Pain
Workers Journal of Sport and Leisure Studies. 2009;0:1021-8.

10. Starrett K, Cordoza G. Becoming a supple leopard. Las Vegas: Victory Belt; 2015.

11. Hicks GE, Fritz JM, Delitto A, McGill SM. Preliminary development of a clinical prediction rule for determining which patients with low back pain will respond to a stabilization exercise program. Arch Phys Med Rehabil. 2005;86:1753-62.

12. Chen L, Chen J, Peng Q, Chen J, Zou Y, Liu G. Effect of Sling Exercise Training on Balance in Patients with Stroke: A Meta-Analysis. PloS one. 2016;11(10):e0163351.

13. Chamorro C, Armijo-Olivo S, De la Fuente C, Fuentes J, Javier Chirosa L. Absolute Reliability and Concurrent Validity of Hand Held Dynamometry and Isokinetic Dynamometry in the Hip, Knee and Ankle Joint: Systematic Review and Meta-analysis. Open Med(Wars). 2017;12:359-75.

14. Reeves NP, Cholewicki J. Modeling the human lumbar spine for assessing loads, stability, and risk of injury. Crit Rev Biomed Eng. 2003;31:73-139..

15. McGill SM, Karpowicz A. Exercises for spine stabilization: motion/motor patterns, stability progressions and clinical technique. Arch Phys Med Rehabil. 2009;90:118-26.

16. Shnayderman I, Katz-Leurer M. An aerobic walking programme versus muscle strengthening programme for chronic low back pain: a randomized controlled trial. Clin Rehabil. 2013;27:207-14.

17. Cynn HS, Oh JS, Kwon OY, Chung HY. Effects of lumbar stabilization using a pressure biofeedback unit on muscle activity and lateral pelvic tilt during hip abduction in sidelying. Arch Phys Med Rehabil. 2006;87:1454-8.

18. Comerford MJ, Mottram SL. Functional stability re-training: principles and strategies for managing mechanical dysfunction. Man Ther. 2001;6:3-14.

19. Beneck GJ, Story JW, Donald S. Postural Cueing to Increase Lumbar Lordosis Increases Lumbar Multifidus Activation During Trunk Stabilization Exercises: Electromyographic Assessment Using Intramuscular Electrodes. J Orthop Sports Phys Ther. 2016;46:293-9. 
20. Cowling EJ, Steele JR, McNair PJ. Effect of verbal instructions on muscle activity and risk of injury to the anterior cruciate ligament during landing. Br $\mathrm{J}$ Sports Med. 2003;37:126-30.

21. Bressel E, Willardson JM, Thompson B, Fontana FE. Effect of instruction, surface stability, and load intensity on trunk muscle activity. J Electromyogr Kinesiol. 2009;19:e500-4.

22. Hayden JA, van Tulder MW, Malmivaara A, Koes BW. Exercise therapy for treatment of non-specific low back pain. Cochrane Database Syst Rev. 2005: CD000335.

23. Franca FR, Burke TN, Hanada ES, Marques AP. Segmental stabilization and muscular strengthening in chronic low back pain: a comparative study. Clinics (Sao Paulo). 2010;65:1013-7.

24. Shim SY, Park HJ, Lee JM, et al. An overview of pain measurements. Korean J Acupunct. 2007;24: 77-97.

25. Wagner DR, Tatsugawa K, parker D, Young TA. Reliability and utility of a visual analog scale for the assessment of acute mountain sickness. High Alt Med Biol. 2007;8:27-31.

26. Michener LA, Boardman ND, Pidcoe PE, Frith AM. Scapular muscle tests in subjects with shoulder pain and functional loss: reliability and construct validity. Phys Ther. 2005;85:1128-38.

27. Roy JS, MacDermid JC, Woodhouse LJ. Measuring shoulder function: a systematic review of four questionnaires. Arthritis Rheum. 2009;61:623-32.

28. Allison GT, Fukushima S. Estimating three-dimensional spinal repositioning error: the impact of range, posture, and number of trials. Spine (Phila Pa 1976). 2003;28:2510-6.

29. Ji MK, Choung SD, Park KN, Kwon OY. Comparison of Lumbar Joint Reposition Error When Sitting in Upright and Slouched Positions for Five Minutes. Phys Ther Kor. 2013;20:20-27.

30. Ng, Shamay S, Christina W. "The timed up \& go test: its reliability and association with lower-limb impairments and locomotor capacities in people with chronic stroke." Arch Phys Med Rehabil. 2005;86: 1641-7.
31. Marshall PW, Murphy BA. Core stability exercises on and off a Swiss ball. Arch Phys Med Rehabil. 2005;86:242-9.

32. McGill SM, Karpowicz A. Exercises for spine stabilization: motion/motor patterns, stability progressions, and clinical technique. Arch Phys Med Rehabil. 2009;90:118-26.

33. Gong WT, Lee SY. The effects of lumbar vertebrae mobilization and lumbar stabilizing exercise on lumbar muscle strength. J Korean Acad Orthop Man Physi Ther. 2007;13:21-30.

34. Kwag KI, Lim JH. The Effects of Stabilization Exercise and Stretching Exercise on Muscle Strength and Pain of Patients with Lower Back Pain. Journal of the Korean Academy of Clinical Electrophysiology. 2011;9:39-46.

35. Hides JA, Jull GA, Richardson CA. Long-term effects of specific stabilizing exercises for first-episode low back pain. Spine (Phila Pa 1976). 2001; 26:E243-8.

36. Rubinstein TC, Giladi N, Hausdorff JM. The power of cueing to circumvent dopamine deficits: a review of physical therapy treatment of gait disturbances in Parkinson's disease. Mov Disord. 2002;17:1148-60.

37. Belkhiria C, De Marco G, Driss T. Effects of verbal encouragement on force and electromyographic activations during exercise. J Sports Med Phys Fitness. 2018;58:750-7.

38. Peters ML, Vlaeyen JW, Weber WE. The joint contribution of physical pathology, pain-related fear and catastrophizing to chronic back pain disability. Pain. 2005;113:45-50. 